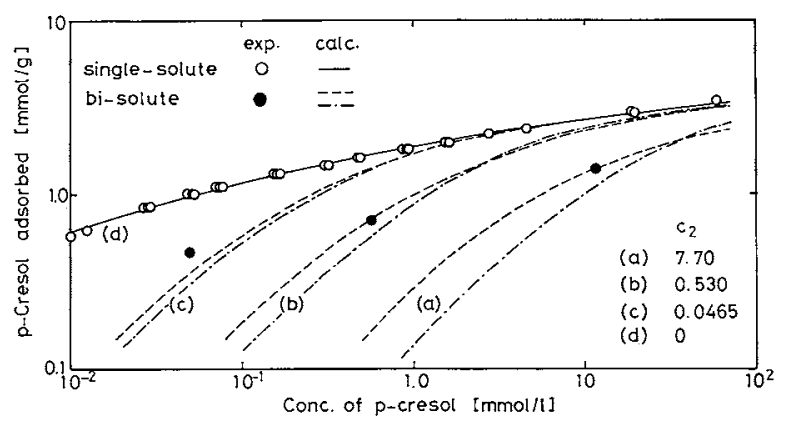

--. calculated with $A_{12}=9.2$ and $A_{21}=8.7$

-- calculated with $A_{12}=A_{21}=1$

Fig. 3 Adsorption from aqueous multi-solute system: p-cresol(1)-p-chlorophenol(2) at $25^{\circ} \mathrm{C}$

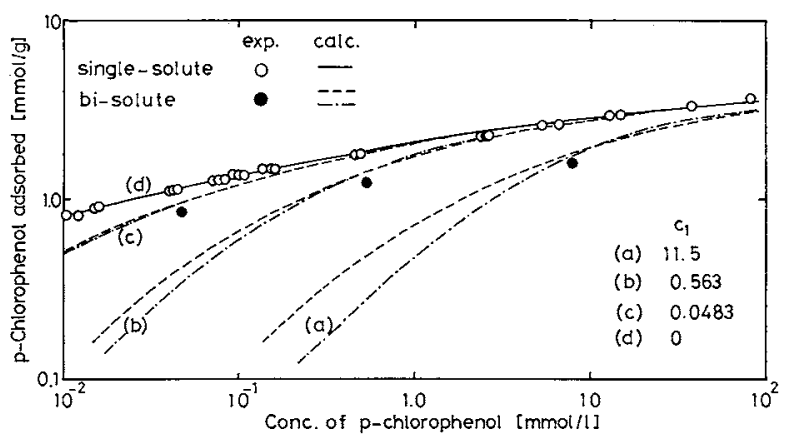

--- calculated with $\Lambda_{12}=9.2$ and $\Lambda_{21}=8.7$

--- calculated with $A_{12}=A_{21}=1$

Fig. 4 Adsorption from aqueous multi-solute system: p-cresol(1)-p-chlorophenol(2) at $25^{\circ} \mathrm{C}$

$\begin{array}{lll}n_{i}^{\circ, \infty} & =\text { maximum moles of solute } i \text { adsorbed } & {[\mathrm{mmol} / \mathrm{g}]} \\ n_{T} & =\text { total moles of solutes adsorbed } & {[\mathrm{mmol} / \mathrm{g}]}\end{array}$
$n_{T}^{\infty}=$ maximum total moles of solutes adsorbed

[ $R$ [mmol $/ \mathrm{g}$ ]

$R \quad=$ gas constant $\quad[\mathrm{J} / \mathrm{mol} \cdot \mathrm{K}]$

$T \quad=$ absolute temperature $\quad[\mathrm{K}]$

$x_{i} \quad=$ mole fraction of component $i$ in adsorbed phase $\left(=n_{i} / \sum_{i} n_{i}, i=1,2,3\right) \quad$ [-]

$z_{i} \quad=$ mole fraction of solute $i$ in water-free adsorbed phase $\left(=n_{i} / \sum_{i} n_{i}, i=1,2\right) \quad[-]$

$\gamma_{i} \quad=$ activity coefficient of solute $i$ in adsorbed phase

$\theta_{i} \quad=$ fractional coverage of solute $i$

$A_{i j}, \Lambda_{j i}=$ Wilson's parameters for interaction between $i$ and $j$ in adsorbed phase $\quad[-]$

$\pi \quad=$ spreading pressure $\quad[\mathrm{N} / \mathrm{m}]$

$\langle$ Superscripts〉

$\begin{array}{ll}\circ & =\text { single-solute system } \\ \infty & =\text { value at maximum adsorption limit }\end{array}$

$\langle$ Subscripts〉

$i, j, k=$ component $i, j, k$

$T \quad=$ total

$1,2=$ adsorbates (organic solutes)

$3=$ water

Literature Cited

1) Radke, C. J. and J. M. Prausnitz: Ind. Eng. Chem., Fundam., 11, 445 (1972).

2) idem: AIChE J., 18, 761 (1972).

3) Suwanayuen, S. and R. P. Danner: ibid., 26, 68 (1980).

4) idem: ibid., 26, 76 (1980).

(A part of this paper was presented at the Utsunomiya Meeting, July 1981 and the 15th Autumn Meeting, October 1981, of The Soc. of Chem. Engrs., Japan.)

\title{
FORMATION OF HYDRAZINE BY PHOTOLYSIS OF AMMONIA IN A FLOW SYSTEM
}

\author{
TATSUYa OKAZAKI, Hiromu HAYASHI, EuI KAWANISHI and YoshIAKI KONISHI \\ Department of Chemical Engineering, Tokushima University, Tokushima 770
}

In industry, hydrazine $\left(\mathrm{N}_{2} \mathrm{H}_{4}\right)$ has been manufactured from ammonia $\left(\mathrm{NH}_{3}\right)$ by a chlorine-oxidation process. However, it is the disadvantage of this process that a large amount of salt is also produced together with the $\mathrm{N}_{2} \mathrm{H}_{4}$ (in the ratio of $6 \mathrm{~kg}$ salt to $1 \mathrm{~kg}$ $\mathrm{N}_{2} \mathrm{H}_{4}$ hydrate). Considerable energy is then spent in the distillation separation of the product. Alternatives have been developed to overcome these shortcomings of the chlorine oxidation process. One is the ketazine process, which is based on an aerial oxidation ${ }^{2-4)}$ or

Received December 4, 1981. Correspondence concerning this article shoutd be addressed to T. Okazaki. E. Kawanishi is now with Nippon Shinyaku Corp., Kyoto 601 hydrogen peroxide oxidation ${ }^{7)}$ of $\mathrm{NH}_{3}$, the other is the direct process from $\mathrm{NH}_{3}$, e.g. the $\mathrm{NH}_{3}$-photolysis process, which is discussed in this note.

$\mathrm{NH}_{3}$ decomposes into $\mathrm{N}_{2} \mathrm{H}_{4}$ by photolysis at the wavelengths $185-225 \mathrm{~nm}$. The work of McDonald et al. ${ }^{6}$, and Groth and Rommel ${ }^{11}$ involves this route. They obtained $\mathrm{N}_{2} \mathrm{H}_{4}$ selectively under reduced pressures in a closed recycling system, although the reaction rate was not measured. Mantell et al. ${ }^{5}$ (Kellogg Co., Ltd.) have claimed that $\mathrm{N}_{2} \mathrm{H}_{4}$ is produced by photolysis of a mixture of nitrous oxide $\left(\mathrm{N}_{2} \mathrm{O}\right)$ and $\mathrm{NH}_{3}$. This has been considered to activate $\mathrm{N}_{2} \mathrm{O}$ rather than $\mathrm{NH}_{3}$. We have studied the rate of photolysis of $\mathrm{NH}_{3}$ 
in a flow system, under the conditions of atmospheric pressure and room temperature, with and without the presence of $\mathrm{N}_{2} \mathrm{O}$.

\section{Experimental}

Figure 1 shows a schematic diagram of the apparatus. The quartz spiral reactors $(3 \mathrm{~mm} \phi \times 0.5 \mathrm{~m}$ and $1.0 \mathrm{~m})$ are irradiated with a low-pressure mercury lamp (LPML, Ushio, UL-1-70Q, 70W), a high-pressure mercury lamp (HPML, Toshiba, H-400P, 40W) and a xenone lamp (Toshiba, XL-500F, ozone-free) under nitrogen $\left(\mathrm{N}_{2}\right)$ circumstances. The absorption spectra of $\mathrm{NH}_{3}$ and $\mathrm{N}_{2} \mathrm{O}$ are measured with a doublebeam spectrophotometer (Hitachi, Model-1200-20) in cylindrical quartz cells $(50 \mathrm{~mm} \times 20 \mathrm{~mm})$. A commercial $\mathrm{NH}_{3}$ gas $(99.991 \%$ of purity) is supplied to the reactors at a given flow rate. The effluent gas from the reactor enters a water-scrubber, and then the volume of insoluble gas $(V)$ is measured. The molar ratio $(R)$ of hydrogen $\left(\mathrm{H}_{2}\right)$ to $\mathrm{N}_{2}$ in the insoluble gas is determined with a gas chromatograph (Hitachi, 063-TCD, Molecular-Sieve 5A). From the $\mathrm{NH}_{3}$ feed rate $\left(V_{0}\right)$ together with $V$ and $R$, a one-pass conversion of $\mathrm{NH}_{3}\left(X_{A}=2 \times 10^{2}(R-3)\left(V / V_{0}\right) /(R+1)\right)$ is determined. Changing the stopcock $\mathrm{C}_{2}$ in Fig. 1, the effluent gas is washed with an ice-cooled $10 \%$ aqueous-acetone solution. This converts $\mathrm{N}_{2} \mathrm{H}_{4}$ to acetone azine quantitatively. The azine is then determined with a gas chromatograph (Hitachi, 163-FID, PEG4000 ) and the selectivity to $\mathrm{N}_{2} \mathrm{H}_{4}\left(S_{H}\right)$ is estimated.

\section{Results and Discussion}

Figure 2 shows the absorption spectra of $\mathrm{NH}_{3}$ and $\mathrm{N}_{2} \mathrm{O}$ in the range of wavelengths from 185 to $225 \mathrm{~nm}$. The extinction coefficient of $\mathrm{N}_{2} \mathrm{O}$ was found to be one60 th that of $\mathrm{NH}_{3}$. Mantell et al. ${ }^{5}$ recommended a molar ratio of $\mathrm{N}_{2} \mathrm{O}$ to $\mathrm{NH}_{3}$ less than one-fifth in feed gas. From the spectrophotometric aspect, however, $\mathrm{N}_{2} \mathrm{O}$ is considered to contribute little to initiating the reaction.

LPML emits resonant light at the wavelengths of 185 and $254 \mathrm{~nm}$. In a batch system, $70 \%$ of $\mathrm{NH}_{3}$ is decomposed into a water-insoluble gas, containing $75.6 \pm 0.2 \%$ of $\mathrm{H}_{2}$, in an hour. This shows the preferential decomposition to $\mathrm{N}_{2}$ and $\mathrm{H}_{2}$. In a flow system, the cumulative volume of water-insoluble gas increases at a constant rate corresponding to various feed rates of $\mathrm{NH}_{3}$. This verifies the steady rates of photolysis of $\mathrm{NH}_{3} . \quad X_{A}$ and $S_{H}$ are plotted against residence time $(\theta)$ for two reactors in Fig. 3. $X_{A}$ is as low as $0.17 \%$, even at $\theta=12$ seconds. Because of the log$\log$ plot, the difference in $X_{A}$ between the two reactors $(0.50$ and $1.0 \mathrm{~m})$ seems to be larger at shorter $\theta$. However, it is not clear at present how significant this difference is. $S_{H}$ increases with decreasing in $\theta$ and

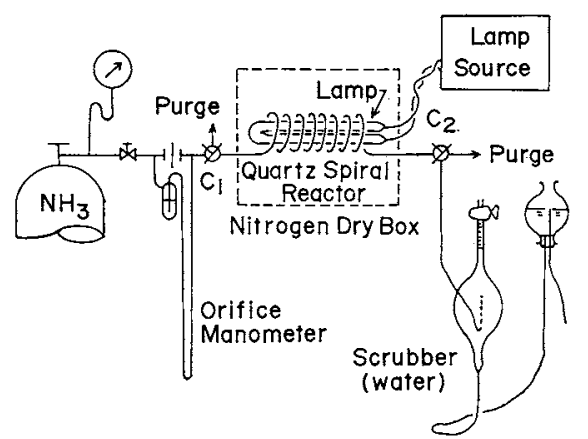

Fig. 1 Apparatus used for Photolysis of $\mathbf{N H}_{3}$

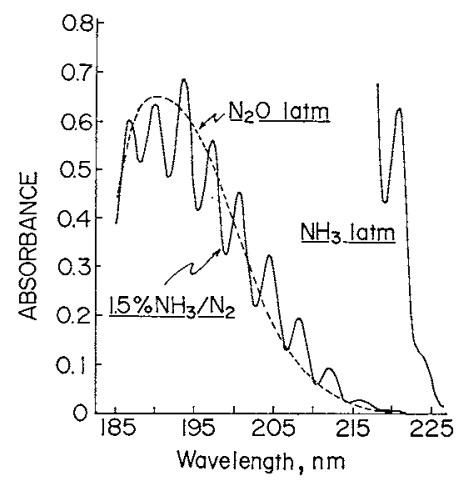

Fig. 2 Absorption spectra of $\mathrm{NH}_{3}$ and $\mathrm{N}_{2} \mathrm{O}$

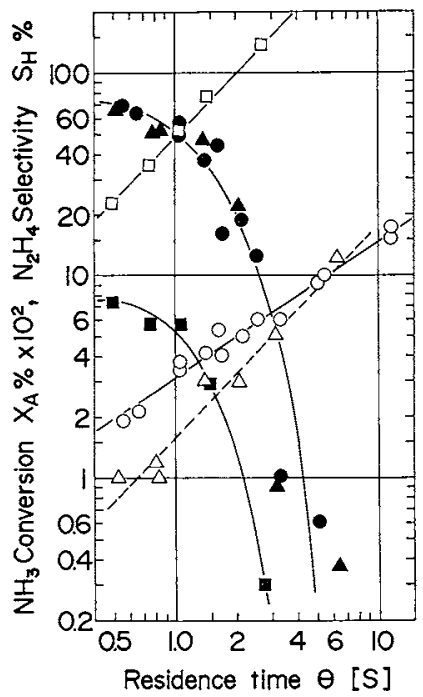

open symbol: $X_{A}$, closed symbol: $S_{H}$, circle: LPML $1.0 \mathrm{~m}$, triangle: LPML $0.5 \mathrm{~m}$, square: HPML $1.0 \mathrm{~m}$

Fig. 3 Effect of Residence time on $X_{A}$ and $S_{I I}$

reaches to $68 \%$ at 0.53 seconds, and the curves for the two reactors agree with each other. The steep degradation in $S_{H}$ suggests a consecutive decomposition of $\mathrm{N}_{2} \mathrm{H}_{4}$. Ambient air suppresses both $X_{A}$ and $S_{H}$, as shown in Fig. 4, with generation of ozone in ambient atmosphere. This is due to the fact that oxygen $\left(\mathrm{O}_{2}\right)$ and $\mathrm{NH}_{3}$ absorb light at $185 \mathrm{~nm}$, but transmit it at $254 \mathrm{~nm}$, while $\mathrm{N}_{2} \mathrm{H}_{4}$ absorbs light at both wavelengths. 


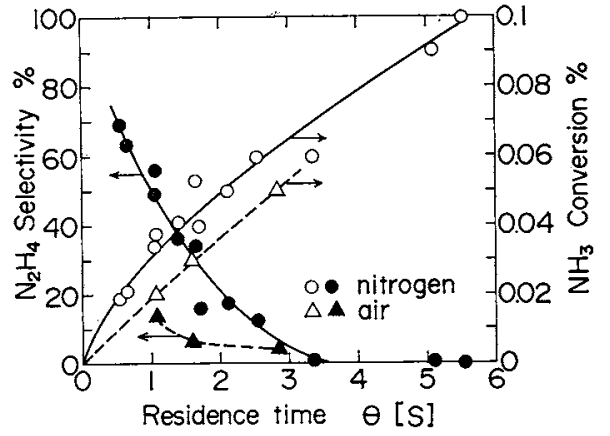

Fig. 4 Effect of ambient gas, air and nitrogen on $X_{A}$ and $S_{H}$

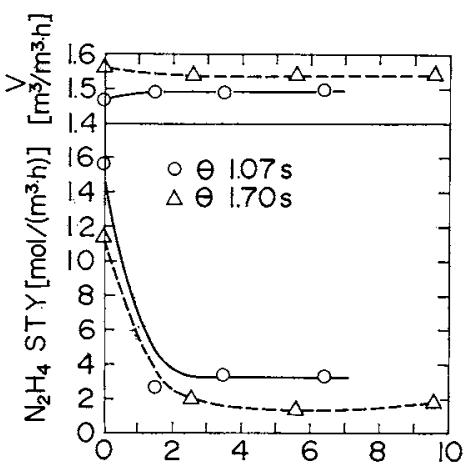

$\mathrm{N}_{2} \mathrm{O} \%$ in feed gas \%

Fig. 5 Effect of $\mathrm{N}_{2} \mathrm{O}$ added to $\mathrm{NH}_{3}$ on $\mathrm{N}_{2} \mathrm{H}_{4}$ STY and V

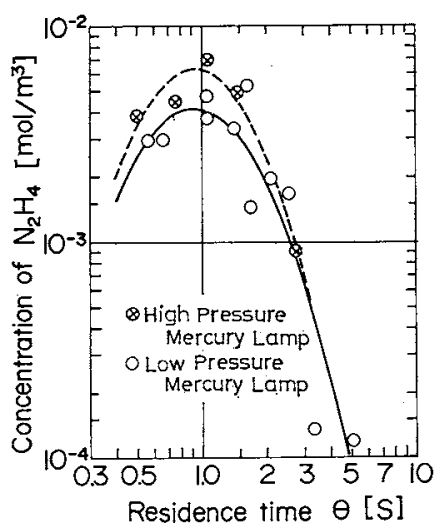

Fig. 6 Concentration of $\mathrm{N}_{2} \mathrm{H}_{4}$ in the effluent gas

Addition of $1.5-9.9 \% \mathrm{~N}_{2} \mathrm{O}$ to $\mathrm{NH}_{3}$ decreases spacetime-yield $(S T Y)$ of $\mathrm{N}_{2} \mathrm{H}_{4}$, although $V$ is kept unchanged, as illustrated in Fig. 5. The contribution of $\mathrm{N}_{2} \mathrm{O}$ to the formation of $\mathrm{N}_{2} \mathrm{H}_{4}$ is still in question.

The xenone lamp does not decompose $\mathrm{NH}_{3}$ without generation of ozone in an aerial ambient atmosphere.
HPML emits light in the range of wavelengths from 185 to $580 \mathrm{~nm}$. The $X_{A}$ for HPML is $10-20$ times higher than that of LPML, but the $S_{H}$ is as low as from one-10th to one-20th that of LPML. This is illustrated in Fig. 3.

The concentrations of $\mathrm{N}_{2} \mathrm{H}_{4}$ in the effluent gas $\left(C_{H}\right)$ from the reactor with either LPML or HPML are found to be almost the same, as shown in Fig. 6. $C_{H}$ reaches a maximum at about 0.9 seconds, and then sharply decreases with time. A radical chain reaction is considered to take place in the photolysis of $\mathrm{NH}_{3}$. Between the irradiated zone and ice-cooled aqueous acetone solution there is a dark zone, where the photolyses of $\mathrm{NH}_{3}$ and $\mathrm{N}_{2} \mathrm{H}_{4}$ stop but the consecutive decomposition of $\mathrm{N}_{2} \mathrm{H}_{4}$ by radicals does not. This is known as the photochemical after-effect. The results depicted in Fig. 6 can be interpreted on the basis of unsteady-state reaction kinetics.

\section{Acknowledgment}

The financial assistance of Scientific Research Foundation of the Ministry of Education, Science and Culture, Japan (Grant No. 56,045,090) is gratefully acknowledged.

\section{Nomenclature}

$$
\begin{aligned}
& C_{H} \quad=\text { molar concentration of hydrazine in effluent } \\
& \text { gas } \quad\left[\mathrm{mol} / \mathrm{m}^{3}\right] \\
& R \quad=\text { molar ratio of hydrogen to nitrogen in } \\
& \text { water-insolubl gas [-] } \\
& S_{H} \quad=\text { molar selectivity to hydrazine } \quad[\%] \\
& \text { STY }=\text { space-time yield of hydrazine } \quad\left[\mathrm{mol} /\left(\mathrm{m}^{3} \cdot \mathrm{h}\right)\right] \\
& V \quad=\text { issue rate of water-insoluble gas } \quad\left[\mathrm{m}^{3} /\left(\mathrm{m}^{3} \cdot \mathrm{h}\right)\right] \\
& V_{0} \quad=\text { feed rate of ammonia gas } \quad\left[\mathrm{m}^{3} /\left(\mathrm{m}^{3} \cdot \mathrm{h}\right)\right] \\
& X_{A} \quad=\text { conversion of ammonia in one pass } \quad[\%] \\
& \theta \quad=\text { residence time in reactor } \quad[\mathrm{s}]
\end{aligned}
$$

\section{Literature Cited}

1) Groth, W. and H. J. Rommel: Z. Phys. Chem. (N.F.), 45, 96 (1965).

2) Hayashi, H., K. Kawasaki, M. Fujii, A. Kainoh, and T. Okazaki: J. Catal., 41, 367 (1976).

3) Hayashi, H., A. Kainoh, M., Katayama, K. Kawasaki and T. Okazaki: Ind. Eng. Chem., Prod. Res. Dev., 15, 299 (1976).

4) Hayashi, H., M. Mori, N. Shigemoto and T. Okazaki: ibid., 17, 128 (1978).

5) Mantell, R. M., O. J. Piesia and R. S. Pratt: U.S.Pat., 2,753,300 (July, 3, 1956).

6) McDonald, C. C., A. Kahn and H. E. Gunning: J. Chem. Phys., 22, 908 (1954).

7) Ugine-Kuhlmann: Brit. Pat., 1,358,389 (July 3, 1974). 